\title{
229. Free Air Gravity Anomalies at Sea around Japan measured by the Tokyo Surface Ship Gravity Meter (1961-1969)
}

\author{
By Yoshibumi Tomoda,*) Jiro SEGAWA,*) \\ and Atsushi ToKuHIRo**) \\ (Comm. by Chuji Tsubor, M. J. A., Nov. 12, 1970)
}

Gravity meters used. For the purpose of gravity measurements at sea on board an ordinary surface ship, several types of gravity meter were designed, tested and improved between 1957 and 1961 . The final satisfactory model was named "Tokyo Surface Ship Gravity Meter" or T.S.S.G. Since 1961 four sets of T.S.S.G. have been built and widely used for gravity surveys: one set belongs to the Hydrographic Department while the other three belong to the Ocean Research Institute, University of Tokyo.

This T.S.S.G. is a kind of string type gravity meter mounted directly on a vertical gyroscope (Tsuboi, Tomoda and Kanamori 1961, Tomoda and Kanamori 1962). The underlying principle of measurement is that the oscillation frequency of the gravity meter string depends on the gravity value at the place. Since the first model was built in 1961, various points of it have been improved (Tomoda, Ozawa and Segawa 1968, Segawa 1970). One of the most important improvements is in its data processing device. In the newest set-up on board the Hakuho-maru of the Ocean Research Institute, two gravity meters are placed side by side and countings coming from each of the gravity meters are directly put into an electronic computer. After necessary numerical processes by the computer, final gravity values are automatically printed out at an interval of $10 \mathrm{~min}$. In doing this, oscillation of the gravity meter string is converted into digital form by means of frequency counters and fed to the realtime-control of the electronic computer at an interval of about $0.5 \mathrm{sec}$. From these data "instantaneous" vertical accelerations are calculated taking into account nonlinear characteristics of the gravity meter string. Accelerations within the sampling interval of $0.5 \mathrm{sec}$ are interpolated to obtain continuous vertical acceleration values. Gravity values are then obtained by combining the frequency of the string and the vertical motion of the ship by means of a digital low pass filter.

*) Ocean Res. Inst., Univ. of Tokyo.

**) Hydrographic Department, Maritime Safety Agency. 
Four ships were used for gravity measurements in the adjacent seas of Japan: the Meiyo (300 tons) and the Takuyo (770 tons) of the Hydrographic Department, the Umitaka-maru (1450 tons) of Tokyo University of Fisheries and the Hakuho-maru (3200 tons) of the Ocean Research Institute, University of Tokyo. Voyage tracks of these ships are shown in Fig. 1. Since all the cruises were designed for multi-purposes, none of them has been used exclusively for the gravimetric purpose; in fact some of the gravity measurements were made when the ship was cruising in pursuit of shrimps.

The correction methods which were applied in the earlier measurements for the second order effect of the elastic tension in the string gravity meter were found not to be satisfactory, so that these were all reprocessed. Fig. 2 shows the distribution of free air gravity anomalies, based on all the available data; the recalculated earlier measurements and the more recent ones. The contour lines on land were drawn using the results of gravity surveys by the Earthquake Research Institute, University of Tokyo and the Geographical Survey Institute (Tsuboi, Jitsukawa and Tajima 1953, 1954 and 1956 and Geographical Survey Institute 1957, 1964 and 1965).

General feature of free air gravity anomaly distributions. For the convenience of seeing the general trend of the anomaly distribution, the areas in which the positive anomalies are larger than $50 \mathrm{mgal}$ are hatched and those in which the negative free air anomalies are smaller than -50 mgal are dotted in Fig. 3. The axes of "high" and "low" are shown by full lines and dashed lines respectively.

The distribution is characterized by zones of large positive and negative anomalies in Northeast Japan trending north to south. On the other hand in Southwest Japan, east to west trend of anomalies

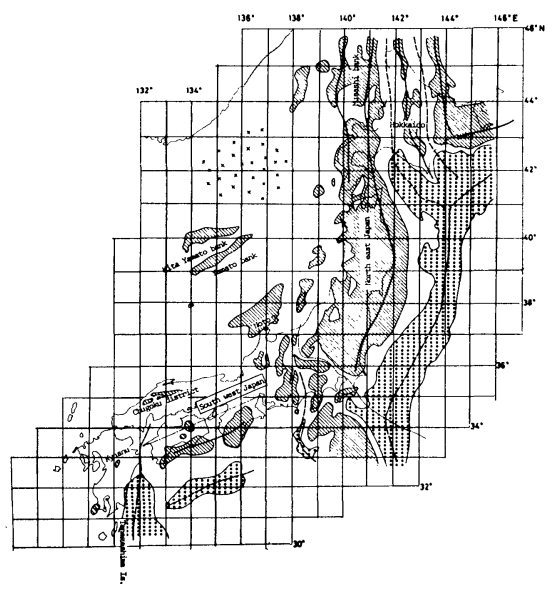

Fig. 3 


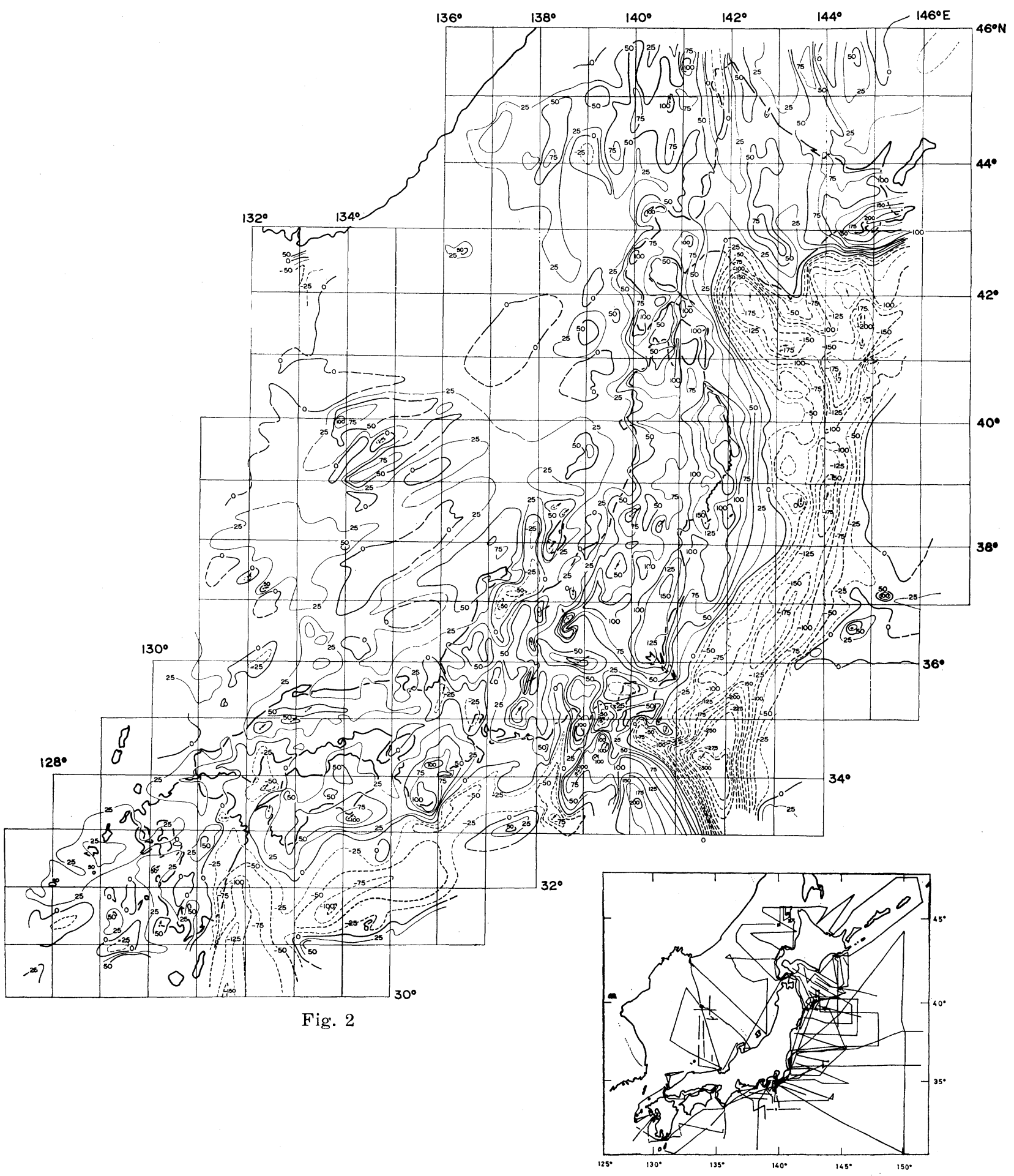

Fig. 1 
is remarkable.

Positive anomalies in Northeast Japan run to the north and are connected to the Musashi bank in the northern part of the Japan Sea, maximum values being found to be about $150 \mathrm{mgal}$ along the Pacific coast of Northeast Japan. To the east of this positive zone there is a negative zone which is also trending north to south. This remarkable negative zone, with a minimum of $-190 \mathrm{mgal}$, is associated with the Japan Trench. The axis of this negative zone makes branches at $41^{\circ} \mathrm{N}, 144^{\circ} \mathrm{E}$. One of the branches continues to the Tatar Strait between Sakhalin and Primorsk district of Siberia running through west of the central axis of Hokkaido. The minimum anomaly in this branched axis is about $-180 \mathrm{mgal}$. Considering that the water is very shallow along the branched axis (only $200 \mathrm{~m}$ at the point of the minimum anomaly) this branch seems to correspond to the axis of a palaeo-trench. Parallel to this trend two positive axes exist in Hokkaido district. One is associated with central axis of Hokkaido and is connected to the western peninsula of Sakhalin, and the other on its east is connected to the eastern peninsula of Sakhalin. A large positive zone in the southeast coast of Hokkaido is a junction point connecting the above mentioned north-to-south positive trend with the east-to-west trend of a positive zone associated with the Kuril island arc.

In Southwest Japan positive anomalies run east to west along the coast, maximum values being about $100 \mathrm{mgal}$ along the Pacific coast of this district. A negative zone found at the Nankai Trough is in a close association with these positive zones.

The inner zone of Southwest Japan and southwestern part of the Japan Sea seem to have similar characteristics. Positive anomalies are found at central axis of Chugoku district, Noto Peninsula and its north, and the Yamato and Kita Yamato banks. There are found no conspicuous negative zones in the Japan Sea, except that at the continental margin of Primorsk district of Siberia in which a small scale gravimetric trench of about $-60 \mathrm{mgal}$ seems to exist approximately 20 N.M. south of Nakhodka.

Free air gravity anomaly in the Japan Sea is, as a whole, positive, its average being 10-20 mgal. In the northern part of the Japan Sea the water is about $3000-3500 \mathrm{~m}$ deep and the bottom is comparatively flat. Free air gravity anomaly in the northern basin is zero on an average and is as smooth as the bottom topography. The area is shown by $\underset{x \times x}{x \times x}$ in Fig. 3. Recent seismic investigation of the Japan Sea implies that the crust is oceanic in its central part. If so, considering that the free air anomalies are nearly zero and that the water depth is about $3500 \mathrm{~m}$ there, the density of rocks composing 
the upper several tens of kilometers of the mantle must be smaller by about $0.1 \mathrm{gr} / \mathrm{cm}^{3}$ than the density of rocks composing the upper mantle of the Pacific.

In the western part of Southwest Japan, there is a conspicuous negative zone off east coast of Kyushu running north to south. The magnitude of the negative anomaly is comparable to that at the trench. Its axis runs about 40 N.M. east of Tanegashima island and about 20 N.M. east of the east Pacific coast of Kyushu. Minimum value is found to be $-150 \mathrm{mgal}$ at the shelf of only $200 \mathrm{~m}$ in depth. This is interpreted, concerning its origin, as concealing the existence of a palaeo-trench, similarly to the case of the negative zone south of Hokkaido.

\section{References}

1) C. Tsuboi, T. Tomoda, and H. Kanamori: Continuous measurements of gravity on board a moving surface ship. Proc. Japan Acad., 37, 571-576 (1961).

2) Y. Tomoda and H. Kanamori: Tokyo surface ship gravity meter $\alpha-1$. J. Geodetic Soc. Japan, 7, 116-146 (1962).

3) Y. Tomoda, K. Ozawa, and J. Segawa: Measurement of gravity and magnetic field on board a cruising vessel. Bul. Ocean Res. Inst., Univ. Tokyo, No. 3 (1968).

4) J. Segawa: Gravity measurements at sea by use of the T.S.S.G., Part I. Data processing method of the T.S.S.G. J. Phys. Earth, 18, 19-49 (1970).

5) —_: Gravity measurements at sea by use of the T.S.S.G., Part II. Results of the measurements. J. Phys. Earth, 18 (1970).

6) C. Tsuboi, A. Jitsukawa, and H. Tajima: Gravity survey along the lines of presise levels throughout Japan by means of a worden gravimeter, Part I-VIII. Bul. Earthq. Res. Inst. Univ. Tokyo, 4 (1953, 1954, 1955, 1956).

7) Geographical Survey Institute: Gravity survey in Japan, I-V. Bul. Geogr. Sur. Inst., 4 (1955), 5 (1957), 9 (1964) 10 (1965). 